\title{
ARTIGOS
}

\section{Eficiência e atividade enzimática elicitada por metil jasmonato e silicato de potássio em cana- de-açúcar parasitada por Meloidogyne incognita}

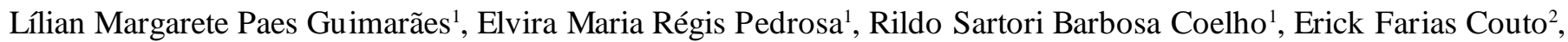 \\ Sandra Roberta Vaz Lira Maranhão ${ }^{1} \&$ Andréa Chaves ${ }^{1}$
}

${ }^{1}$ Departamento de Agronomia, Universidade Federal Rural de Pernambuco, Dois Irmãos, 52171-900, Recife, PE. ${ }^{2}$ Laboratório de Fitopatologia, Empresa Pernambuc ana de Pesquis a Agropecuária-IPA, Bongi, 50761-000, Recife, PE.

Autora para correspondência: Elvira Maria Régis Pedrosa (elvira.pedrosa@dtr.ufrpe.br)

Data de chegada: 10/07/2008. Aceito para publicação em: 29/07/2009.

\section{RESUMO}

Guimarães, L.M.P., Pedrosa, E.M.R., Coelho, R.S.B., Couto, E.F., Maranhão, S.R.V.L. \& Chaves, A. Eficiência e atividade enzimática elicitada por metil jasmonato e silicato de potássio em cana-de-açúcar parasitada por Meloidogyne incognita. Summa Phytopathologica, v.36, n.1, p.11-15, 2010.

O presente estudo teve como objetivo avaliar o efeito de metil jasmonato e silicato de potássio sobre o parasitismo de Meloidogyne incognita na variedade RB863129 de cana-de-açúcar (Saccharum sp.) e a atividade enzimática da peroxidase e $\beta-1,3$-glucanase elicitada, em condições de cas a de vegetação. Metil jasmonato diminuiu significativamente o número de ovos por grama de raiz, mas não afetou à biomassa da parte aérea da planta. Sete dias após a aplicação, os dois indutores afetaram a atividade de $\beta$-glucanase na plantas parasitadas e, aos 14 e 21 dias, promoveram variações significativas nos níveis de peroxidase e $\beta$-1,3-gluc anase, muito embora, ao contrário da peroxidase, a atividade $\beta$-1,3-glucanase não diferiu entre plantas inoculadas e não inoculadas.

Pala vras-chave adicionais: Nematóide das galhas, Saccharum sp., peroxidase, $\beta$-1,3-glucanase, indução de resistência

\section{ABSTRACT}

Guimarães, L.M.P., Pedrosa, E.M.R., Coelho, R.S.B., Couto, E.F., Maranhão, S.R.V.L. \& Chaves, A. Efficiency and enzymatic activity elicited by methyl jasmonate and potassium silicate on sugarcane under Meloidogyne incognita parasitism. Summa Phytopathologica, v.36, n.1, p.11-15, 2010.

The present study had as objective to evaluate methyl jasmonate and potassium silicate effect on Meloidogyne incognita parasitism in sugarcane (Saccharum sp.) variety RB863129 and peroxidase and $\beta$ 1,3-glucanase activity elicited, under greenhouse. The effect of Methyl jasmonate and potassium silicate did not affect shoot biomass. Methyl jasmonate and potassium silicate significantly decreased eggs number per gram of roots. Seven days after application, both inducers affected b-glucanase activity in parasited plants and at 14 and 21 days, inducers promoted significant variations in peroxidase e $\beta$-1,3-glucanase levels in plants under parasitism, although, inversely to peroxidase, $\beta$-1,3glucanase activity did not differ between inoculated and non inoculated plants.

Keywords: root-knot nematode, Saccharum sp., peroxidase, $\beta$-1,3-glucanase, resistance induction

A cana-de-açúcar (Saccharum sp.) é uma cultura de grande expressão econômica no mundo e o Brasil é o maior produtor, tendo colhido 420.120.992 milhões de toneladas (9). No nordeste do Brasil, nematóides do gênero Meloidogyne presentes nos canaviais reduzem drasticamente a produtividade agrícola devido às condições edafoclimáticas favoráveis ao parasitismo (15). Sendo comumente encontradas nos canaviais de Pernambuco e Estados vizinhos as espécies $M$. javanica (Treub, 1885) Chitwood e M. incognita (Kofoid \& White, 1919) Chitwood (5, 14, 15).

Devido ao difícil controle, geralmente são adotadas medidas de manejo integrado, fundamentando-se no uso de nematicidas, rotação de culturas e pousio (10). Sendo o cultivo de variedades resistentes um dos mais importantes componentes para manejo eficiente de nematóides em sistemas integrados, embora nem sempre estejam disponíveis para todo patossis tema. No entanto, quando a planta não apresenta mecanismos de defesa eficientes, a resistência pode ser ativada por indutores e expressa no local do sítio de infecção, ou sistemicamente, após o ataque do patógeno, caracterizando a resistência sistêmica adquirida (13).

Muitas vantagens são observadas com a utilização de indutores, tais como: efetividade contra diversos patógenos; es tabilidade devido a ação de diferentes mecanismos de resistência, e caráter sistêmico. Ativados na presença de patógenos, esses mecanismos incluem a morte programada de células, produção de metabólitos secundários antimicrobianos (fitoalexinas), produção de proteínas relacionadas com a patogênese (PR-proteínas), como as quitinases, $\beta$-1,3-glucanases, proteínas RIPS, defensinas e lignific ação da parede celular. As PRproteínas são acumuladas no local específico após a indução, atuando direta ou indiretamente contra o fitopatógeno $(19,25)$.

Dentre os indutores com uso potencial contra nematóide se 
encontram o metil jasmonato e o silicato de potássio. O ácido jasmônico, forma fisiologicamente ativa do jasmonato, tem papel importante na cas cata de eventos que ocorre no processo de indução, causando direta ou indiretamente o acúmulo de metabólitos secundários (11). Em tecidos de plantas tratadas com jasmonato, efeitos distintos são apresentados por expressão das proteínas induzidas por jasmonatos (PIJs), que incluem as tioninas e as proteinases $(7,21$, 26).

O silício é o segundo elemento mais abundante da crosta terrestre, apenas superado pelo oxigênio. Trabalhos relacionados com o papel do silício na resistência de plantas a doenças têm apresentado resultados promissores em vários patossistemas. O silício é absorvido pelas plantas como ácido monosilícico, porém o teor é variável entre espécies. A observação do aumento da atividade enzimática, como peroxid ases e polifenoloxidase e a presença de fitoalexinas em plantas tratadas com silício levantaram a hipótese do envolvimento na indução das reações de defesa da planta (22). Em es tudos conduzidos em cana-deaçúcar foram relatados a redução de sintomas de manchas foliares, como ferrugeme mancha parda (27). O objetivo da presente pesquisa foi avaliar o efeito de metil jasmonato e silicato de potássio, em diferentes concentrações, sobre o parasitismo de $M$. incognita em cana-de-açúcar e atividade enzimática da peroxidase e $\beta$-1,3-glucanase.

\section{MATERIALE MÉTODOS}

A pesquisa foidesenvolvida em casa de vegetação do Laboratório de Fitonematologia da Universidade Federal Rural de Pernambuco. A variedade estudada foi RB863129, desenvolvida pelo Programa de Melhoramento Genético da Cana-de-açúcar - RIDESA (Rede Interuniversitária para o Desenvolvimento do Setor Sucroalcooleiro), altamente suscetível a $M$ incognita (3). As mudas foram obtidas do cultivo de ápices caulinares originadas da biofábrica da Usina Santa Tereza, Goiana-PE, com aproximadamente 90 dias de idade. Os indutores, metil jasmonato na concentração de 0,1 e $0,2 \mathrm{~mL} / \mathrm{Le}$ silicato de potássio na concentração de 10 e $20 \mathrm{~mL} / \mathrm{L}$ foram aplicados por pulverizações nas folhas das plantas, 15 dias após transplantio para vasos. As inoculações foram efetuadas 10 dias após a aplicação do indutor, sendo o inóculo constituído por 20.000 ovos de M. incognita por planta. Plantas não induzidas e inoculadas foram usadas como testemunhas relativas e, como testemunhas absolutas, plantas não induzidas e não inoculadas. Os tratamentos foram denominados da seguinte forma: Test $(\mathrm{cn})=$ testemunha inoculada; Test $(\mathrm{sn})=$ testemunha absoluta; MJ1 (cn) = inoculada e induzida com metil jasmonato $0,1 \mathrm{~mL} / \mathrm{L} ; \mathrm{MJ} 2(\mathrm{cn})$ = inoculada e induzida com metil jasmonato $0,2 \mathrm{~mL} / \mathrm{L} ; \mathrm{MJ} 1(\mathrm{sn})=$ não inoculada e induzida com metil jasmonato $0,1 \mathrm{~mL} / \mathrm{L} ; \mathrm{MJ} 2(\mathrm{sn})=$ não inoculada e induzida com metil jasmonato $0,2 \mathrm{~mL} / \mathrm{L} ; \mathrm{SP} 1(\mathrm{cn})=$ inoculada e induzid a com silicato de potássio $10 \mathrm{~mL} / \mathrm{L}$; SP2 $(\mathrm{cn})$ = inoculada e induzida com silicato de potássio $20 \mathrm{~mL} / \mathrm{L}$; SP1 (sn) = não inoculada e induzida com silicato de potássio $10 \mathrm{~mL} / \mathrm{L} ; \mathrm{SP} 2(\mathrm{sn})$ = não inoculada e ind uzida com silicato de potássio $20 \mathrm{~mL} / \mathrm{L}$. O delineamento estatístico foi do tipo inteiramente casualizado, com seis tratamentos e cinco repetições.

As plantas foram regadas diariamente. Decorridos 90 dias após a inoculação, as plantas foram cuidadosamente retiradas do solo, para determinação do peso da biomas sa fresca da parte aérea e raízes. Os sistemas radiculares foram lavados, por imersão em água limpa, e as raízes removidas cuidadosamente para minimizar perdas de massa de ovos. Para extração de ovos do nematóide, utilizou-se o método de
Hussey \& Barker (12). Lâminas de Peters e microscopia óptica foram empregadas para contagens.

Os dados obtidos foram submetidos à análise de variância e as médias comparadas por contrastes ortogonais ao nível de 5\% de probabilidade. Para a análise, os dados relativos ao número de ovos por planta, ovos por grama de raiz e a biomassa das plantas foram transformados para $\sqrt{ }(\mathrm{X}+0,5)$.

A atividade enzimática foi avaliada aos 7, 14 e 21 dias após a inoculação, utilizando-se três plantas por tratamentos para cada época de coleta. Amostras de 1,5 g de folhas foram maceradas em almofariz com Nitrogênio líquido, adicionando-se $1 \%(\mathrm{v} / \mathrm{v})$ de polivinilpirrolidone (PVP) e 6,0 mL de tampão acetato de sódio 0,1 M, pH 5,0, o qual continha $1 \mathrm{mM}$ de EDTA. Os extratos foram centrifugados a 14.000 rpm por 25 minutos a $4{ }^{\circ} \mathrm{C}$ e o sobrenadante foi transferido para microtubos de $3,0 \mathrm{~mL}$ e armazenados a $-80^{\circ} \mathrm{C}(6)$, para a determinação da atividade da peroxidase e $\beta$-1,3-glucanase.

A peroxidase foi estimada com base na avaliação do delta de absorbância (D) proporcionado com a oxidação do guaiacol $\left(\mathrm{C}_{3} \mathrm{H}_{8} \mathrm{O}_{2}\right)$ na presença do peróxido de hidrogênio (6). Para ocorrer a reação pipetou-se numa cuba espectrofotométrica, $50 \mu \mathrm{L}$ de guaiacol $(0,02 \mathrm{M})$, $1,0 \mathrm{~mL}$ do tampão acetato $(0,1 \mathrm{M})$ e $0,25 \mathrm{~mL}$ de peróxido de hidrogênio $(0,38 \mathrm{M})$. Agitou-se a mistura levemente, a qual serviu para zerar o espectrofotômetro. Pipetou-se $50 \mu \mathrm{L}$ do extrato enzimático, agitouse levemente e realizou-se as leituras a $470 \mathrm{~nm}$ por 4 minutos.

A atividade da $\beta$-1,3-glucanase foi avaliada através da quantificação da glicose liberad a com a hidrólise da laminarina. Para isto, pipetou-se 50 ì do extrato enzimátic o em tubo de ensaio, adicionou-se $50 \mu \mathrm{L}$ do tampão acetato de sódio $(100 \mathrm{mM} / \mathrm{pH} 5,0)$ e $50 \mu \mathrm{L}$ de laminarina $(4,0$ $\mathrm{mg} / \mathrm{mL}$ ). Realizou-se o teste em branco adicionando-se água destilada no lugar da laminarina. Em seguida, o material foi incubado a $40{ }^{\circ} \mathrm{C}$ por 1 hora. Após este período, acrescentou-se 2,0 mL de uma solução do ácido dinitrosalićlíco (DNSA). A mistura foi aquecida a $100^{\circ} \mathrm{C}$ por 5 minutos e resfriou-se em banho de gelo. Posteriormente, foram realizadas leituras espectrofotométricas a $570 \mathrm{~nm}$ e comparadas com padrões de glicose. A curva padrão de glicose utilizada foi constituída das seguintes concentrações $0,50,200,300,600,1.200,2.400 \mathrm{mg} / \mathrm{L}$.

Os dados obtidos nos dois sistemas enzimáticos estudados foram submetidos à análise de variância e as médias comparadas por contrastes ortogonais ao nível de $5 \%$ de probabilidade.

\section{RESULTADOS E DISCUSSÃO}

O peso da biomass a fresca da parte aérea e raízes das plantas inoculadas não diferiu $(\mathrm{P}>0,05)$ das não inoculadas (Tabela 1$)$, indicando que o parasitismo do nematóide não afetou o desenvolvimento da cana, 90 dias após a inoculação. Por outro lado, a ação dos indutores nas plantas inoculadas resultou em significativa $(\mathrm{P} \leq 0,05)$ redução da biomassa fresca da parte aérea e raízes, (Tabela 1). Muito embora os indutores de maneira geral não reduziram $(\mathrm{P} \leq 0,05)$ o número de ovos do nematóide por planta, o metil jasmonato e silicato de potássio foram eficientes em reduzir $(\mathrm{P} \leq 0,05)$ o número de ovos por grama de raiz, sendo esta variável mais precisa para avaliação da eficiência dos indutores (Tabela 1).

A atividade de peroxidase aos 7,14 e 21 dias diferiu $(\mathrm{P} \leq 0,05)$ quando comparou-se testemunhas inoculadas com não inoculadas (Tabela 2), ocorrendo maior atividade dessa enzima em plantas inoculadas aos 14 e 21 dias (Figura 1). O efeito do metil jasmonato e silicato de potássio sobre a atividade da peroxidase em plantas 
Tabela 1. Efeito da aplicação e diferentes dosagens de metil jasmonato (MJ) e silicato de potássio (SP) sobre a reprodução de Meloidogyne incognita e biomassa da cana-de-açúcar na variedade RB863129

\begin{tabular}{|c|c|c|c|c|c|c|c|c|}
\hline \multirow[t]{2}{*}{ Contraste } & \multicolumn{2}{|c|}{$\operatorname{BFR}(\mathbf{g})$} & \multicolumn{2}{|l|}{$\mathbf{O P}$} & \multicolumn{2}{|l|}{ OGR } & \multirow[b]{2}{*}{ Média } & \\
\hline & Média & NS & Média & NS & Média & NS & & \\
\hline Testemunha inoculada $\times$ Testemunha não inoculada & $64,00 \times 45,00$ & 0,140 & $9,00 \times 6,00$ & 0,08 & - & - & - & - \\
\hline Plantas inoculadas: sem $\mathrm{MJ} \times$ com MJ & $64,00 \times 45,00$ & 0,043 & $9,00 \times 7,00$ & 0,019 & $7.100 \times 4.200$ & 0,254 & $798 \times 590$ & $<0,01$ \\
\hline Plantas inoculadas: sem SP $\times$ com SP & $64,00 \times 36,50$ & 0,016 & $9,00 \times 14,00$ & 0,013 & $7.100 \times 8.225$ & 0,475 & $798 \times 541$ & $<0,01$ \\
\hline Metil jasmonato: $0,1 \mathrm{~mL} / \mathrm{L} \times 0,2 \mathrm{~mL} / \mathrm{L}$ & $51,00 \times 40,00$ & 0,694 & $6,9 \times 7,05$ & 0,372 & $6.450 \times 5.500$ & 0,394 & $555 \times 638$ & 0,015 \\
\hline Silicato de potássio: $10 \mathrm{~mL} / \mathrm{L} \times 20 \mathrm{~mL} / \mathrm{L}$ & $36,25 \times 37,5$ & 0,528 & $13,3 \times 7,40$ & 0,013 & $5.200 \times 11.250$ & $<0,01$ & $587 \times 496$ & 0,949 \\
\hline $\mathrm{CV}(\%)$ & - & 16,70 & - & 16,75 & - & 7,10 & - & 4,72 \\
\hline
\end{tabular}

BFPA= biomassa fresca da parte aérea; $\mathrm{BFR}$ = biomassa fresca da raiz; $\mathrm{OP}=$ número de ovos por planta; OGR = número de ovos por grama de raiz; NS = Nível de significância.

Tabela 2. Atividade enzimática de peroxidase e $\beta$-1,3-glucanase induzidas por metil jasmonato (MJ) e silicato de potássio (SP) em plantas de canade-açúcar variedade RB863129, parasitadas por Meloidogyne incognita, aos 7, 14 e 21 dias após a inoculação Peroxidase

\begin{tabular}{|c|c|c|}
\hline \multirow[b]{2}{*}{ Contraste } & \multicolumn{2}{|c|}{ Nível de significância } \\
\hline & Peroxidase & $\beta$-1,3-glucanase \\
\hline \multicolumn{3}{|l|}{7 dias } \\
\hline Testemunha inoculada $\times$ Testemunha não inoculada & $<0,01$ & 0,257 \\
\hline Plantas não inoculadas: sem MJ $\times$ com MJ & 0,218 & 0,589 \\
\hline Plantas não inoculadas: $\mathrm{sem} \mathrm{SP} \times \operatorname{com} \mathrm{SP}$ & 0,002 & 0,863 \\
\hline Plantas inoculadas: sem $\mathrm{MJ} \times$ com $\mathrm{MJ}$ & 0,140 & 0,016 \\
\hline Plantas inoculadas: sem SP $\times$ com SP & 0,944 & 0,020 \\
\hline Plantas inoculadas: MJ $0,1 \mathrm{~mL} / \mathrm{L} \times \mathrm{MJ} 0,2 \mathrm{~mL} / \mathrm{L}$ & 0,236 & 0,640 \\
\hline Plantas inoculadas: SP $10 \mathrm{~mL} / \mathrm{L} \times \mathrm{SP} 20 \mathrm{~mL} / \mathrm{L}$ & 0,086 & 0,091 \\
\hline $\mathrm{CV}(\%)$ & 10,59 & 12,58 \\
\hline \multicolumn{3}{|l|}{14 dias } \\
\hline Testemunha inoculada $\times$ Testemunha não inoculada & $<0,01$ & 0,059 \\
\hline Plantas não inoculadas: sem $\mathrm{MJ} \times$ com MJ & 0,110 & 0,273 \\
\hline Plantas não inoculadas: $\operatorname{sem~} \mathrm{SP} \times$ com $\mathrm{SP}$ & 0,942 & 0,276 \\
\hline Plantas inoculadas: sem $\mathrm{MJ} \times$ com $\mathrm{MJ}$ & $<0,01$ & $<0,01$ \\
\hline Plantas inoculadas: sem $\mathrm{SP} \times$ com SP & $<0,01$ & $<0,01$ \\
\hline Plantas inoculadas: MJ $0,1 \mathrm{~mL} / \mathrm{L} \times \mathrm{MJ} 0,2 \mathrm{~mL} / \mathrm{L}$ & 0,027 & 0,831 \\
\hline Plantas inoculadas: SP $10 \mathrm{~mL} / \mathrm{L} \times \mathrm{SP} 20 \mathrm{~mL} / \mathrm{L}$ & 0,333 & 0,428 \\
\hline $\mathrm{CV}(\%)$ & 15,98 & 19,85 \\
\hline \multicolumn{3}{|l|}{21 dias } \\
\hline Testemunha inoculada $\times$ Testemunha não inoculada & $<0,01$ & 0,569 \\
\hline Plantas não inoculadas: sem MJ $\times$ com MJ & $<0,01$ & 0,029 \\
\hline Plantas não inoculadas: sem $\mathrm{SP} \times$ com $\mathrm{SP}$ & 0,847 & 0,075 \\
\hline Plantas inoculadas: sem $\mathrm{MJ} \times$ com $\mathrm{MJ}$ & $<0,01$ & $<0,01$ \\
\hline Plantas inoculadas: sem $\mathrm{SP} \times$ com $\mathrm{SP}$ & $<0,01$ & 0,017 \\
\hline Plantas inoculadas: MJ $0,1 \mathrm{~mL} / \mathrm{L} \times \mathrm{MJ} 0,2 \mathrm{~mL} / \mathrm{L}$ & $<0,01$ & $<0,01$ \\
\hline Plantas inoculadas: SP $10 \mathrm{~mL} / \mathrm{L} \times \mathrm{SP} 20 \mathrm{~mL} / \mathrm{L}$ & $<0,01$ & $<0,01$ \\
\hline $\mathrm{CV}(\%)$ & 12,92 & 18,76 \\
\hline
\end{tabular}

parasitadas foi detectado aos 14 e 21 dias (Tabela 2), evidenciando menor atividade enzimática nas plantas que receberam os indutores, exceto aos 21 dias após a inoculação, quando o metil jasmonato a 0,1 $\mathrm{mL} / \mathrm{L}$ elicitou maior atividade da peroxidase (Tabela 2, Figura 1).

Ao contrário daperoxidase, não foi detectada diferença na atividade da $\beta$-1,3-glucanase entre testemunhas inoculadas e não inoculadas em nenhuma época de avaliação. No entanto, a partir do sétimo dia ocorreram variações significativas na atividade dessa enzima em plantas parasitadas e induzidas com metil jas monato ou silicato de potássio. Aos 7 e 21 dias a atividade da enzima foi maior nas plantas parasitadas e induzidas, em relação às parasitadas não induzidas. A maior atividade de $\beta$-1,3-glucanase ocorreu aos 14 dias em plantas parasitadas e não induzid as (Figura 1). Diferenças entre as dosagens de ambos indutores foram significativas aos 21 dias após a inoculação, ocorrendo maior atividade enzimática nas maiores dosagens (Tabela 2).

A indução de resistência a nematóides caracteriza-se pela interrupção ou alongamento do ciclo do parasito, que pode atuar de forma direta ou indireta no estímulo da eclosão, capacidade do juvenil localizar e invadir a planta hos pedeira, indução e manutenção do sítio de alimentação e, conseqüentemente, desenvolvimento de fêmeas adultas e produção de ovos (4). As respostas em raízes de cana-deaçúcar em seguida a aplicação de metil jasmonato em tecido foliar, podem ocorrer pela ativação do jasmonato via caminho genético, ou pela manipulação e aplicação específica do produto, aumentado o potencial de resistência da planta a microrganismos (2).

Segundo Oka \& Cohen (17), em trigo (Triticum aestivum L.) e cevada (Hordeum vulgare L.) tratadas com ácido DL- $\beta$-amino-nbutírico houve formação do sítio de alimentação, sugerindo que o mecanismo de resistência induzida pelo indutor é expresso em estádios posteriores ao estabelecimento dos nematóides das galhas em seus hospedeiros. No entanto, o sítio de alimentação nas raízes tratadas com DL- $\beta$-amino-n-butírico não foi suficiente para suprir as necessidades nutricionais do nematóide, ou algumas substâncias inibitórias ao desenvolvimento do nematóide foram produzidas ou simplesmente liberadas nesses sítios de alimentação. Segundo Fernandes (8), a peroxidase é uma enzima comum em plantas e o aumento frequiente nas respostas aos ataques dos patógenos, mostra o envolvimento dessa enzima no mecanismo de defesa.

Owen et al. (20) estudaram o efeito do acibenzolar-S-metil contra $M$. incognita e $M$. javanica em videira (Vitis spp. L.) e não observaram efeito tóxico direto contra o nematóide. No patossistema M. incognitatomateiro (Lycopersicon esculentum Mill.), a aplicação do acibenzolar$\mathrm{S}$-metil, antes da inoculação do nematóide promoveu reduções significativas no número de galhas, massas de ovos e ovos por grama de raiz em relação ao controle (24). No entanto em estudos conduzidos por Oka et al. (16) no patossistema Meloidogyne-tomateiro, o ácido jasmônico e o metil jasmonato, via pulverização em folhas ou molhamento do solo, não induziu resistência, discordando dos resultados ora obtidos. Contudo, muitas evidências indicam que mudanças no padrão da atividade enzimática da peroxidase estão relacionadas com defesa local e sistêmica da planta, isso por que essa enzima atua na reparação de ferimentos, na lignificação e na deposição de suberina (23).

Oliveira et al. (18) estudaram o comportamento de genótipos de caupi resis tentes e suscetíveis à meloidoginose quanto à produção de peroxidase e observaram que a cultivar TE97-411-1E, resistente a $M$. incognita, apresentou um aumento significativo da atividade enzimática em resposta a infecção, sugerindo a participação dessa enzima no mecanismo de defesa das plantas. Estudos desenvolvidos por Atkinson (1) comprovaram indução sistêmica da atividade da peroxidase em folhas de batata (Solanum tuberosum L.) cujas raízes estavam infectadas por Globodera rostochiensis (Wollenweber, 1923) Mulvey \& Stone, 


\section{Peroxidase}

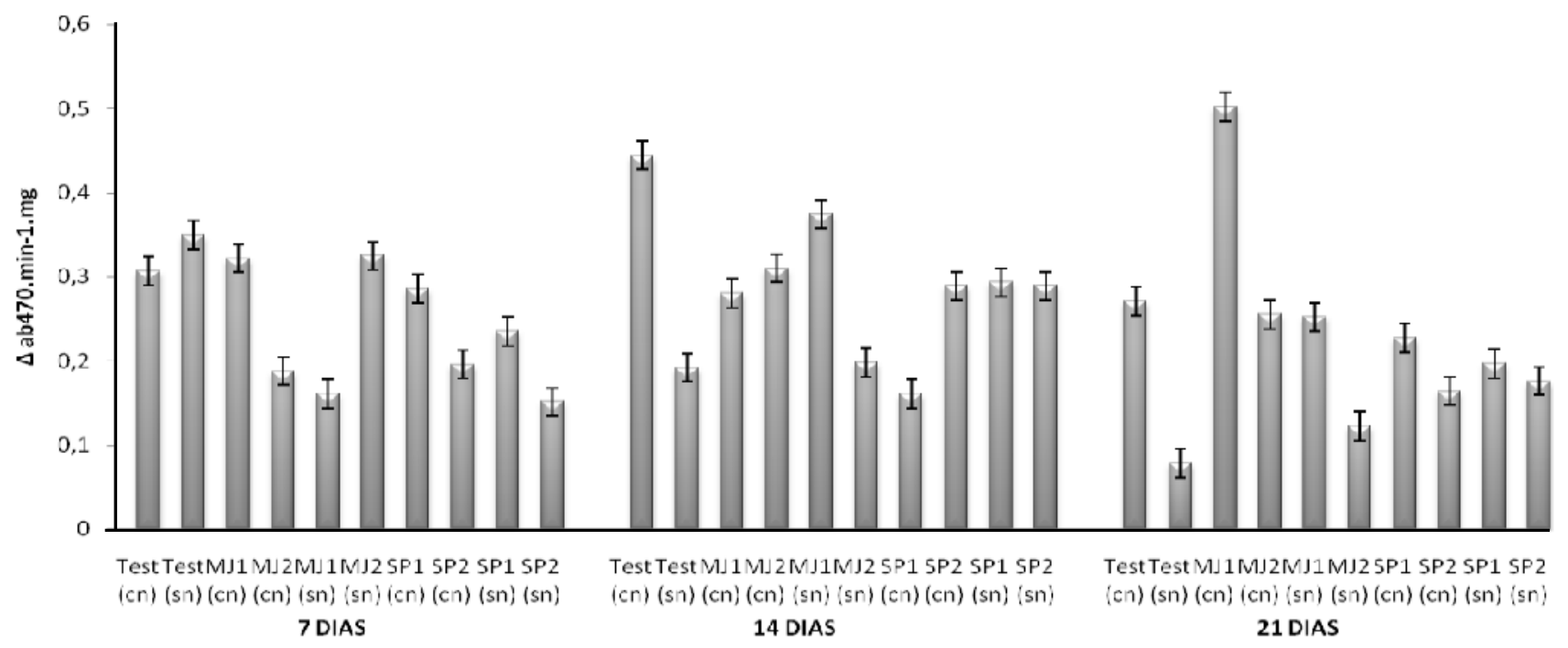

$\beta$-1,3-gluc anase

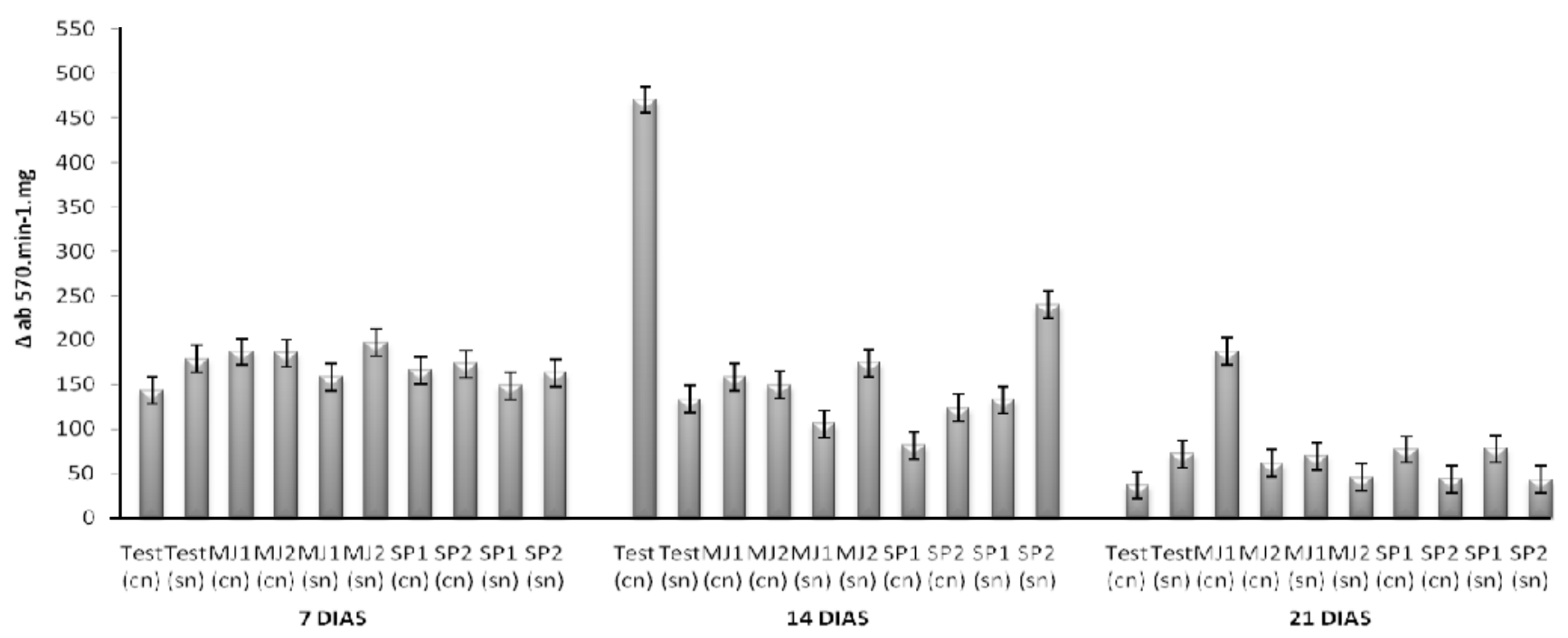

Figura 1. Médias originais das atividades enzimáticas de peroxidase e $\beta$-glucanase aos 7,14 e 21 dias após a aplicação dos indutores. $($ Test $(* \mathrm{cn})=$ testemunha inoculada; Test $(* \mathrm{sn})=$ testemunha; $\mathrm{MJ} 1(\mathrm{cn})=$ metil jasmonato $0,1 \mathrm{~mL} / \mathrm{L} ; \mathrm{MJ} 2(\mathrm{cn})=$ metil jasmonato $0,2 \mathrm{~mL} / \mathrm{L} ; \mathrm{MJ} 1(\mathrm{sn})=$ não inoculada e induzida com metil jasmonato $0,1 \mathrm{~mL} / \mathrm{L} ; \mathrm{MJ} 2(\mathrm{sn})=$ não inoculada e induzida com metil jasmonato $0,2 \mathrm{~mL} / \mathrm{L} ; \mathrm{SP} 1(\mathrm{cn})=$ silicato de potássio $10 \mathrm{~mL} /$ $\mathrm{L} ; \mathrm{SP} 2(\mathrm{cn})=$ silicato de potássio $20 \mathrm{~mL} / \mathrm{L} ; \mathrm{SP} 1(\mathrm{sn})=$ não inoculada e induzida com silicato de potássio $10 \mathrm{~mL} / \mathrm{L} ; \mathrm{SP} 2(\mathrm{sn})=$ não inoculada e induzida com silicato de potássio $20 \mathrm{~mL} / \mathrm{L}$. ( ${ }^{*} \mathrm{cn}=\mathrm{com}$ nematóide; sn=sem nematóide)

1976. Por outro lado, estudos realizados em videiras parasitadas com $M$. javanica e $M$. incognita indicaram que acibenzolar-S-metil não afetava diretamente o nematóide, mas quando avaliou-se a resposta de defesa da planta, ocorreu aumento da $\beta$-1,3-glucanase, 28 dias após a inoculação (20).

A utilização de metil jasmonato e silicato de potássio reduziram o número de nematóides por grama de raiz. O parasitismo de $M$. incognita aumentou a atividade da peroxidase, aos 14 e 21 dias após a inoculação. Os indutores também afetaram a atividade enzimática, observou-se que plantas tratadas com metil jasmonato, 21 dias após a inoculação, apresentaram altos valores desta enzima. A enzima $\beta$-1,3-glucanase apresentou maior atividade nas plantas parasitadas e não induzidas, aos 14 dias após a inoculação. Conclui-se então que os indutores afetaram diretamente o nematóide e a atividade enzimática na planta, como provável reação de defesa.

\section{AGRADECIMENTOS}

À Coordenação de Aperfeiçoamento de Pessoal de Nível Superior (CAPES), pela concessão de bolsa recebida.

\section{REFERÊNCIAS BIBLIOGRÁFICAS}

1. Atkinson, H.J. Plant-Nematode interactions: molecular and genetics basis. In: Kohmoto, K. Singh, U.S.; Singh, R.P. (Eds.) Pathogenesis and host specificity in plant diseases. Oxford, UK. Elsevier Science Ltda. 1995. pp.355-369.

2. Bower, N.I.; Casu, R.E.; Maclean, D.J.; Reverter, A.; Champman, S.C.; Manners, J.M. Transcriptional response of sugarcane roots to methyl jasmonate. Plant Science, v.168, p.761-772, 2005.

3. Chaves, A.; Pedrosa, E.M.R.; Pimentel, R.M.M.; Coelho, R.S.B.; Guimarães, L.M.P.; Maranhão, S.R.V.L. Resistance induction to 
Meloidogyne incognita in sugarcane through mineral organic fertilizers In: Congresso Brasileiro de Fitopatologia, 40., 2007. Maringá. Fitopatologia Brasileira. Brasília: Sociedade Brasileira de Fitopatologia, 2007. v.32, p.S131.

4. Cook, R. Resistance in plants to cyst and root-knot nematodes. Agricultural Zoology Reviews, v.4, p.231-239, 1991.

5. Cruz, M.M.; Silva, S.M.S.; Ribeiro, A.G. Levantamento populacional de nematóides em cana-de-açúcar em áreas de baixa produtividade nos Estados de Alagoas e Sergipe. Nematolologia Brasileira, v.10, p.27-28, 1986.

6. Dann, E.K.; Deverall, B.J. Activation of systemic disease resistance in pea by an avirulent bacterium or a benzothiadiazole, but not a fungal leaf spot pathogen. Plant Pathology, v. 49, p.324332,2000 .

7. Epple, E.E.; Aple, K.; Bohlmann, K. An Arabidopsis thaliana thionin gene is inducible via a signal transduction pathway different from that for pathogenesis related proteins. Plant Physio$\log \mathbf{y}$, v. 109 , p.813-820, 1995.

8. Fernandes, C.F. Estudo da atividade peroxidásica em folhas primárias de feijão-de-corda (Vigna unguiculata (L.) Walp.) cv. Vita 3. 1998. 65 f. Dissertação (Mestrado em Bioquímica) - Universidade Federal do Ceará, Fortaleza, 1998.

9. Food And Agriculture Organization, 2006. FAOASTAT - Agricultural statistics database. Rome: World Agricultural Information Centre, 2006. Disponível em: <http://apps.fao.org>. Acesso em: 02 set .2006.

10. Freitas, L.G. O controle biológico dentro do contexto de manejo integrado de nematóides. Fitopatologia Brasileira, v.28, supl., p.24-30, 2003

11. Gundlach, H.; Muller, M.J; Kutchan, T.M.; Zenk, M.H. Jasmonic acid is a signal transducer in elicitor induced plant cell cultures. Plant Biology, v.89, p.2386-2393, 1992.

12. Hussey, R.S.; Barker, K.R. A comparis on of methods of collecting inocula of Meloidogyne spp., including a new technique. Plant Disease Reporter, v.57, p.1025-1028, 1973.

13. Métraux, J.P. Systemic acquired resistance and salicylic acid: current status of knowledge. European Journal of Plant Patho$\log \mathbf{y}$, v.107, p.13-18, 2001.

14. Moura, R.M.; Almeida, A.V. Estudos preliminares sobre a ocorrência de fitonematóides associados à cana-de-açúcar em áreas de baixa produtividade agrícola no Estado de Pernambuco. Nematologia Brasileira, v.5, p.213-220, 1981.

15. Moura, R.M. Controle integrado dos nematóides da cana-de-açúcar no nordeste do Brasil. In: Congresso Brasileiro de Nematologia, 12., 2000, Uberlândia, Anais. Brasília: Sociedade Brasileira de Nematologia, 2000. p.88-94.
16. Oka, Y.; Cohen, Y.; Spiegel, Y. Local and systemic induced resistance to the root-knot nematode in tomato by DL-b-amino-nbutyric acid. Phythopathology, v.89, p.1138-1143, 1999.

17. Oka, Y.; Cohen, Y. Induced resistance to cyst and root-knot nematodes in cereals by DL--amino-butyric acid. European Journal of Plant Pathology, v.107, p.219-227, 2001.

18. Oliveira, J.T.A.; Andrade, N.C.; Miranda, A.S.M.; Barreto, A.L.H.; Melo, V.M.M.; Fernandes, C.F.; Vasconcelos, I.M.; Silveira, J.A.G.; Cavalcanti, F.R.; Freire-Filho, F.R.; Freire, F.C.O.; Gonçalves, F.J.T. Atividades peroxidásica e â-1,3 glucanásica elicitadas por agentes bióticos causadores de doenças e pelo estresse hídrico em feijão-de-corda [Vigna unguiculata (L.) Walp.]. In: Reunião Nacional de pesquisa de Caupi, 5., 2001.Teresina. Anais. 2001. p. $19-23$.

19. Oliveira, S.M.A.; Dantas, S.A.F.D.; Gurgel, L.M.S. Indução de resistência em doenças pós-colheita em frutas e hortaliças. Revisão Anual de Patologia de Plantas, v.12, p.343-372, 2004.

20. Owen, K.J.; Green, C.D.; Deverall, B.J. Systemic acquired resistance against root-knot nematodes in grapevines. In: International Congress of Plant Pathology, 7., 1998. Perth. Proceedings. 1998. p.38.

21. Pieterse, C.M.J.; Van Wess, S.C.M; Van Pelt, J.A.; Knoester, M.; Laan, R.; Gerrits, N.; Weisbeek, P.J.; Van Loon, L.C. A novel signaling pathway controlling induced systemic resistance in Arabdopsis. The Plant Cell, v.10, p.1571-1580, 1998.

22. Pozza, A.A.A.; Pozza E.A.; Santos, D.M. O silício no controle de doenças de plantas. Revisão Anual de Patologia de Plantas, v.12, p.373-402, 2004.

23. Sijmons, P.C.; Atkinson, H.J.; Wyss, U. Parasitic strategies of root nematodes and associated host cell responses. Annual Review of Phytopathology, v.32, p.235-259, 1994.

24. Silva, L.H.C.P.; Campos, J.R.; Campos, V.P.; Dutra, M.R. Época de aplicação do acibenzolar-S-metil e da abamectina no controle de Meloidogyne sp. em tomateiro. Fitopatologia Brasileira, v. 27, p.194, 2002 .

25. Van Loon, L.C. Induced resistance in plants and the role of pathogenesis-related proteins. European Journal of Plant Pathology, v.103, p.753-765, 1997.

26. Wierstra, I.; Kloppstech, K. Differential effects of methyl jasmonate on the expression on the early light-inducible proteins and other light-regulated genes in barley. Plant Physiology, v.124, p.833-844, 2000.

27. Wong You Cheong, Y.; Heits, A.; De Ville, J. Foliar symptoms of silicon deficiency in the sugarcane plants. In: Congress International Sugar Cane Technology, 14. 1971, New Orleans. Proceedings. 1971. p.766-776. 